\title{
Compatibilidade entre competências individuais e organizacionais: um estudo de caso em uma organização não governamental - ONG
}

\author{
Alysson André Regis de Oliveira, BSc. Adm. \\ Universidade Federal da Paraíba \\ alyssonandre@hotmail.com \\ Celia Cristina Zago, Dra. Eng. \\ PPGA - UFPB \\ celia.zago@terra.com.br
}

\begin{abstract}
Através de uma pesquisa de caráter quali-quantitativo, este estudo objetivou analisar a compatibilidade entre as competências de uma organização não governamental - Projeto Beira da Linha (PBL) - e as competências dos seus talentos como condição para o alcance dos seus objetivos. Fundamentada em um levantamento bibliográfico, a pesquisa é caracterizada como um estudo de caso de enfoque exploratório-descritivo, sendo aplicada junto a dois grupos distintos: os gestores e os demais funcionários. Pudemos concluir com o estudo que há compatibilidade em nível de concepção do que sejam as competências organizacionais e as competências individuais no PBL, mas há pouca sintonia entre as mesmas quando se trata da sua aplicação e operacionalização real, o que, mesmo assim, parece não afetar o sentimento de envolvimento dos membros organizacionais haja vista que o PBL consegue de forma atuante alcançar muitos dos seus objetivos, principalmente aqueles de atuação sócio-educacional.
\end{abstract}

Palavras -chave: competências; ONG; gestão por competências

This present quantitative and qualitative work aimed at the analysis of the competences between a non governmental organization - PROJETO BEIRA DA LINHA* (PBL) and its gifted staff who creates condition to achieve the proposed goals of the organization. Supported by a bibliographical basis this research is characterized as a case study with an exploratory and descriptive focus applied to two different groups: the managers and the workers. It could be concluded that there is a compatibility in what refers to the knowledge of what are organizational competence and individual competence at PBL, however, there is little accomplishment between the groups concerning the real application and functioning, though it seems not to affect the involvement of the staff with the organization once the PBL brilliantly achieves all the proposed aims, specially those on social and educational grounds.

Keywords: competence; NGO; competence management

*Projeto Beira da Linha $=$ On the Boardline Project

\section{Introdução}

Administrar pessoas é uma das tarefas mais complexas das realizadas pelos administradores, posto que exige que se leve em consideração aspectos subjetivos, fazendo desse campo de gerência um desafio contínuo. Destarte a esta dificuldade, a preocupação com a gestão de pessoas vem ocupando um espaço 
cada vez mais evidenciado nas organizações, principalmente pela constatação de que são as pessoas e suas práticas produtivas que determinam a performance organizacional e influenciam a sua capacidade de competitividade e sustentabilidade.

O desempenho organizacional está diretamente relacionado às capacidades de recursos organizacionais e às competências pessoais de cada um dos seus profissionais (MATOS, 2004), levando à máxima de que a pessoa certa no lugar certo pode ser um grande diferencial competitivo. Isso sugere a crescente necessidade por profissionais capazes de desempenhar seus papéis de forma a atender às demandas das organizações.

A busca pela competência profissional nos leva a observar o esgotamento do modelo baseado no treinamento tradicional, de formação exclusivamente técnica, que já não responde mais às necessidades de formação das pessoas e às expectativas das empresas em termos de novas habilidades e atitudes que sejam condizentes com a realidade organizacional, que procura estar em consonância com as exigências do mercado.

A proposta baseada na gestão por competências visa aproximar objetivos organizacionais e pessoais/individuais (profissionais) com um olhar mais atencioso na inserção de novos talentos, suportados pelas competências exigidas e reais. Ela também atenta para a possível sub-utilização dos talentos nas atividades compatíveis com seus conhecimentos, habilidades e atitudes, identificando não só a pessoa certa para o lugar certo, mas o lugar que melhor potencialize os seus talentos (RESENDE, 2002; DUTRA 2002; LE BOTERF, 2003).

A proposta do gerenciamento das competências indica para práticas organizacionais direcionadas para uma gestão mais efetiva e compatível à estratégia competitiva da organização (FLEURY, 2002). Nesse aspecto, contempla-se que o desenvolvimento pessoal pode ser a chave para o aprimoramento das práticas de trabalho e para o comprometimento das pessoas com a organização.

A produtividade de bens ou serviços se torna cada vez mais dependente da gestão de pessoas para que, através destas, os processos sejam desenvolvidos com agilidade e confiabilidade. Um aspecto principal a ser observado é como cada talento se encontra no cenário organizacional e como desenvolve suas atividades, visando melhores resultados por meio de um alto nível de envolvimento das pessoas com suas atribuições.

A bibliografia mostra que um dos dilemas produtivos atuais, independente do tipo ou do tamanho da organização, é o de saber a forma mais eficaz de lidar e gerir as competências organizacionais e o conhecimento daqueles que compõem a organização. Ao mesmo tempo, sugere-se que é necessário para um bom gestor ter a percepção das competências de sua organização e, mais precisamente, de sua equipe, buscando a otimização de seus talentos.

No campo das organizações do terceiro setor, cada vez mais a eficiência e a produtividade têm sido consideradas características básicas, tanto para o cumprimento da responsabilidade social, como para a própria sobrevivência da entidade organizacional. Entretanto, pela sua característica cultural de voluntariado e militância, o senso comum pode mostrar que as competências individuais podem não corresponder às necessidades de desempenho profissional que atendam às competências organizacionais. Desperta-se, portanto, para a necessidade de estudos mais aprofundados que possam elucidar se existe compatibilidade entre as competências organizacionais e dos membros organizacionais, o que, em última instância, passa a ser a condição para sua sobrevivência.

Ter pessoal qualificado com competências para elaborar projetos com gabarito passou a ser a diretriz central, e não mais a militância ou o engajamento anterior à causa em ação. Os antigos militantes foram 
procurar programas de especialização e pós-graduação. A militância é de certa forma um problema para as entidades e é um equívoco buscar por profissionais apenas por esta trajetória (GOHN, 1999, p. 78).

Com esta preocupação, esta pesquisa foi desenvolvida em uma entidade do terceiro setor, caracterizada como Organização Não-Governamental (ONG), denominada "Projeto Beira de Linha" (PBL), com o propósito de elucidar as seguintes questões: há compatibilidade entre as competências organizacionais e as competências pessoais na ONG Projeto Beira da Linha? qual o impacto deste fator nos resultados finais esperados pela organização?.

Assim, o presente estudo teve como objetivo analisar a existência da compatibilidade entre as competências do PBL e dos seus talentos, bem como avaliar sua eficácia para atingir os objetivos dos membros organizacionais. Para tanto, procuramos: a) descrever os objetivos e as competências de uma ONG; b) descrever os objetivos e as competências do PBL; c) verificar a lacuna existente entre o desempenho esperado e o desempenho real dos funcionários; d) perceber se há clareza entre as pessoas do PBL sobre as competências organizacionais e individuais; e) verificar se os resultados alcançados pela organização estão diretamente relacionados ao aproveitamento ótimo das competências individuais de seus componentes.

Para melhor entendimento e procurando cumprir os objetivos deste trabalho, além desta parte introdutória, são apresentados a seguir alguns aspectos teóricos gerais sobre as organizações não- governamentais e sobre o modelo de gestão por competências e são explicados os procedimentos metodológicos que orientaram o estudo, acompanhados dos principais resultados percebidos. Por último, apresentamos as principais conclusões permitidas e algumas sugestões para outras pesquisas que possam dar continuidade à construção do conhecimento na área objeto.

\section{As organizações não-governamentais (ONGs)}

De modo geral, a idéia de trabalho é desenvolvida a partir do entendimento de uma relação tripartite Estado, mercado e sociedade civil, onde a sociedade civil é percebida como terceiro setor, no qual se inscreve as ONGs (WOLFE, 1991 apud FERNANDES, 1996).

Entende-se que a possibilidade da organização da sociedade civil permitiria a construção de esferas públicas, enquanto instâncias de mediação entre o Estado, economia e sociedade. Nessa perspectiva, a sociedade civil é definida como:

O espaço social, onde nascem e organizam-se as associações voluntárias (autônomas em relação ao mercado e ao Estado), chamadas de movimentos sociais ou populares, organizações não-governamentais, grupos de mútua ajuda, entidades filantrópicas e outras do gênero (SCHERER-WARREN, 1994, p.7 apud FERNANDES, 1996, p.40).

No que se refere às ONGs, percebe-se que estas incorporaram no seu discurso a organização e o fortalecimento da sociedade civil como objetivo central da sua atuação, direcionado, de forma geral, para campos da filantropia, desenvolvimento e cidadania. Segundo Fernandes (1996), o debate atual refere-se a essas instituições como novos atores sociais que assumem uma postura política, engajadas em um projeto de transformação social.

Nos últimos anos, tem ocorrido uma proliferação dessas organizações no Brasil, o que revela a importância desse fenômeno. A idéia é a de que elas têm contribuído para a construção de espaços públicos, o que contempla a noção de pluralidade e diversidade presentes no cotidiano dos personagens que formam o terceiro setor, ou melhor, a sociedade civil na contemporaneidade. 
Fernandes (1996) afirma ainda que as disposições legais existentes hoje no Brasil não dão conta da realidade das ONGs no contexto em que elas estão inseridas, podendo-se afirmar que, em relação à classificação jurídico-institucional, estas organizações fazem parte do setor sem fins lucrativos que comporta um universo de instituições, denominadas de sociedades civis, organizações ou entidades, associações, entidades filantrópicas, beneficentes ou de caridade, ONGs e fundações.

Assim, ONG é um termo que evoca o mundo da política, da militância, da cidadania onde se destaca o seu papel na construção de espaços públicos e na consolidação democrática. A expressão "ONG" foi utilizada pela primeira vez na década de 40 pela Organização das Nações Unidas - ONU, para denominar entidades não oficiais que recebiam recursos financeiros para executar projetos de interesses de grupos ou comunidades (BERNARDES e NANNE, 1994 apud FERNANDES, 1996, grifo nosso). No Brasil, esse termo somente ganhou visibilidade entre as décadas de 70 e 80 para designar a emergência de organizações privadas e sem fins lucrativos, atuando em benefício público - através da prestação de serviços às classes populares - tornando-se um fenômeno no continente a partir da década de 1970, sendo que cerca de 68\% delas surgiram depois de 1975 (FERNANDES, 1994).

Fernandes (1994) destaca que o surgimento das ONGs é, talvez, o sintoma mais claro na América Latina das tendências que nos leva a pensar num "terceiro setor", que não passa de um pequeno segmento, mas que as suas características resumem-se com nitidez na idéia do "privado com funções públicas", ou seja, instituições propriamente privadas, mas sem fins lucrativos, sendo que "os lucros eventuais devem ser reinvestidos nas atividades-fim, não cabendo a sua distribuição, enquanto tais, entre os membros da organização" (FERNANDES, 1994, p. 65).

Fernandes (1994) constata em seu estudo que o trabalho feito por essas organizações pode ser subdividido em 17 categorias temáticas, sendo que os campos de atuação menos procurados por elas são:

Criminalidade/Violência/Drogas, Negros e Índios e, dentre os de maior incidência que revelam os campos em que as ONGs têm concentrado as suas energias se destacam as categorias Formação Qualificada/Assessoria (40,6\%) e Educação (36\%). Outros focos medianos mencionados foram: Pesquisa, Desenvolvimento/Promoção Social, Saúde, Mulher, Meio Ambiente, Comunicação, Direitos Humanos, Projetos de Financiamentos, Créditos e Finanças.

Quem são os beneficiados diretos do trabalho das ONGs? Segundo Fernandes (1994), em seu estudo, a comunidade é a resposta mais freqüente. Cerca de um terço de todas as ONGs declaram trabalhar para ela, pois carregam características associadas a este conceito, quais sejam: a valorização de intenções face a face, em vez de uma abordagem formal e burocrática; e a concentração no local de moradia, em vez de no local de trabalho. A combinação destas idéias ajuda a compreender as peculiaridades destas organizações quando dizem: "Trabalhamos para as comunidades".

Ainda como grupos beneficiários podem-se destacar: trabalho, o meio rural, os velhos, os marginalizados, grupos étnicos, dentre outros. As ONGs, com uma agenda de direitos civis, concentram-se nos locais de moradia e têm-se priorizado regiões e funções mais fragilizadas na estrutura social - os pobres, em geral, crianças e mulheres na família, trabalhadores rurais na produção. Cidadãs e militantes, essas organizações exerceram significativo papel na maioria dos movimentos sociais populares urbanos que delinearam o cenário de participação na sociedade civil, trazendo para a cena pública novos personagens, contribuindo decisivamente à queda do regime militar e para a transição democrática no país.

Deve-se destacar que o crescimento das ONGs neste final de milênio é um fenômeno mundial, e o terceiro setor já tem sido caracterizado como um novo setor da economia, o da "economia social". Peter Druker (1994 apud GOHN, 1999) constatou que o terceiro setor foi o que mais cresceu, movimentou recursos, gerou empregos e foi o mais lucrativo na economia norte-americana nos últimos vinte anos. 
Essas entidades que estão se expandindo estruturam-se como empresas, autodenominam-se cidadãs, por se apresentarem sem fins lucrativos e atuarem em áreas de problemas sociais, criando e desenvolvendo frentes de trabalho em espaços públicos não-estatais, cujos resultados podem ser um passaporte à conquista de fundos essenciais para a sua sobrevivência. Assim, os quadros de uma ONG devem ser capacitados para pensar, de maneira estratégica, em como atender as demandas socioculturais que não são satisfeitas pelo mercado, e em como otimizar a adequação das competências dos membros que a compõem para o atendimento de seu papel primordial.

\section{Modelo de gestão por competências}

Desde a década de 80, a sociedade brasileira vem passando por transformações sociais, econômicas, políticas e culturais intensas que resultam em processos de reestruturação produtiva quer seja no setor manufatureiro, quer seja no setor de serviços, levando à necessária alteração dos modelos de gestão das organizações em busca da sustentabilidade.

Apesar de McClelland (1973) ser tido como o precursor das discussões sobre competências nos Estados Unidos, foi a definição emitida por Hamel e Prahalad (1995) como "conjunto de habilidades e tecnologias necessárias para agregar valor a uma organização" que passou a ser o conceito referencial para o novo modelo de gestão que presume o comportamento da empresa e das pessoas que nela trabalham rumo à mesma direção para atingir resultados adequados. Esta proposta deixa claro uma relação íntima de influência entre as competências organizacionais e as individuais, e que o estabelecimento das competências individuais deve estar vinculado à reflexão sobre as competências organizacionais (DUTRA, 2001). Por sua vez, Fleury (2001, p. 98) define competência individual como "Saber agir responsável [...] implica mobilizar, integrar, transferir conhecimentos, recursos habilidade, que agreguem valor econômico à organização e valor social ao individuo".

O modelo de gestão por competências passou a sintetizar as propostas no meio organizacional e acadêmico, as quais unem a estratégia do negócio à gestão estratégica de seu capital intelectual, visto como recurso estratégico da organização. Espera-se que o desenvolvimento de competências possibilite que as práticas organizacionais sejam direcionadas para uma gestão mais efetiva e compatível à estratégia competitiva da empresa. Nesse sentido, a questão de atitudes mais apropriadas à nova realidade proposta é a chave para o aprimoramento das práticas de trabalho e para o envolvimento de todas as pessoas na organização.

A integração entre o modelo de competências e o de gestão de pessoas pode proporcionar ao RH [recurso humano] a sua dimensão estratégica, tendo como conseqüência uma atuação voltada para resultados, auxiliando os estrategistas no cumprimento dos objetivos organizacionais (RUANO, 2003, p. 5).

As organizações buscam atrair e selecionar funcionários que compartilhem com seus valores e crenças e utilizem sistemas de reconhecimento para estimular e tentar garantir os desempenhos considerados adequados e desejáveis às suas realidades. Contudo, segundo Lara e Silva (2004), entre o desempenho real e o desempenho esperado, poderá ocorrer um hiato designado como discrepância de desempenho.

Segundo Teixeira (2002), a competência é um estado específico, e não geral, em que quanto mais conhecimento se adquire, mais competente se torna, porém, sempre relativamente a este tempo e comparativamente às demais pessoas. Isso quer dizer que toda competência é relativa, não há competência absoluta e admite-se também que o estado de incompetência tenha o mesmo caráter de temporalidade. Quando alguém está competente para realizar uma tarefa é porque ela detém um conjunto de conhecimentos mínimos necessários para um desempenho satisfatório desta tarefa. 
Segundo Teixeira (2002), existe as seguintes formas de expressão de competência:

1. Conhecimentos sobre normas e procedimentos específicos (competência para executar);

2. Capacidade para planejar cada passo do processo (competência para planejar);

3. Poder intuitivo (conhecimento intrínseco) para prever fatores imponderáveis (competência para prever);

4. Experiência acumulada na solução de desvios na continuidade do processo (competência para decidir);

Teixeira (2002) conclui que, embora a competência específica seja fundamental para o crescimento profissional, a competência geral - aquela que representa o conjunto de conhecimentos da pessoa - é essencial para sua expressão individual. Os chamados conhecimentos gerais estão novamente no topo da onda e são cada vez mais cobrados dos executivos.

Para Dutra (2001), é necessário ainda olharmos as pessoas por sua capacidade de entrega, pois assim temos uma perspectiva mais adequada (porque mais individualizada) para avaliá-las, para orientar o desenvolvimento delas e para estabelecer recompensas, ou seja, para a implementação de um sistema de gestão de pessoas, que segundo Walker (1980 apud DUTRA, 2001, grifo nosso), é um conjunto de procedimentos que permite à organização identificar "as pessoas mais adequadas às suas necessidades" e, às pessoas, planejar e implementar suas carreiras.

O termo "entrega" refere-se ao fato de o indivíduo sabe agir de maneira responsável e ser reconhecido por isso (FLEURY, 2001). Quando há a entrega de cada pessoa é fácil perceber o grau de envolvimento desta e quais são realmente as suas competências e a compatibilidade das mesmas em relação às competências organizacionais.

Quanto a sua classificação, as competências podem ser (ALBUQUERQUE e OLIVEIRA, 2001):

- Competências Técnicas/ Profissionais: específicas para uma operação, ocupação ou tarefa (desenho técnico, operação de um equipamento, finanças);

- Competências Sociais: saber ser, incluindo atitudes e comportamentos necessários para o relacionamento entre pessoas (comunicação, negociação e trabalho em equipe);

- Competências do Negócio: compreensão do negócio, seus objetivos, relações com o mercado, ambiente sócio-político (conhecimento em negócio, planejamento, orientação para o cliente).

Em nível individual, competências são entendidas como as capacidades, os conhecimentos e as características pessoais que distinguem os profissionais de alto desempenho daqueles de desempenho regular em determinada função (LARA e SILVA, 2004). Por sua vez, a gestão por competências é o sistema gerencial que busca impulsionar os funcionários na competência profissional, acrescentando capacidades e aumentando as já existentes, em busca da potencialização das competências organizacionais.

Lara e Silva (2004) acrescentam que a Gestão por Competências é uma ferramenta que identifica nas organizações, as habilidades e conhecimentos determinantes da eficácia profissional e também as lacunas de qualificação do funcionário para tarefas específicas, além de fornecer recursos para aperfeiçoar suas capacidades. O resultado é um quadro de funcionários mais talentosos e mais produtivos.

Através destes conceitos, pode-se presumir que a Gestão por Competência se propõe a ajudar diretamente no crescimento e amadurecimento da organização, bem como das pessoas nela inseridas e que, conforme o conhecimento das competências organizacionais e a gradativa associação destas às pessoas certas para as atividades esperadas, poder-se-á esperar um melhor nível de entrega e melhores resultados. 
Segundo Ruano (2003), observa-se a existência de duas abordagens sobre competências sendo seguidas na área. Numa delas, a identificação das competências parte da estratégia empresarial, pela definição das competências organizacionais e desdobra-se em competências funcionais (GREEN, 1999; DUTRA, 2001; FLEURY e FLEURY, 2004; RUAS, 2003). Em outra, a identificação se dá no sentido inverso: com a análise das competências de cada profissional formar-se-ia o portfólio de competências organizacionais e, a partir dessa definição, a organização estabelece a sua estratégia no mercado. De acordo com essa abordagem, o novo conhecimento sempre se inicia pelo indivíduo e é transformado em conhecimento organizacional. São as pessoas que, ao colocarem em prática o patrimônio de conhecimentos da organização, caracterizam as competências organizacionais e fazem sua adequação ao contexto (NONAKA, 1991 apud RUANO, 2003).

Ruano (2003) explica que um diagnóstico resumido sobre as competências pode ser realizado em duas etapas. A primeira deve analisar as competências empresariais - competências já instaladas e a adquirir para que a empresa aumente e consolide cada vez mais sua capacidade de competir dentro da estrutura do setor em que atua. A segunda, as competências humanas - competências que precisam ser adquiridas e desenvolvidas na esfera individual para que as organizações tenham sucesso em seus objetivos estratégicos.

As competências organizacionais e individuais estão totalmente relacionadas e não é possível estabelecer as competências individuais sem antes fazer uma reflexão sobre as competências organizacionais. Organizações e pessoas, lado ao lado, proporcionam um processo contínuo de troca de competências (DUTRA, 2001).

Entretanto o ser competente parece ser a condição essencial não só para a competitividade quando se fala em empresas e em mercado concorrencial, mas também quando se menciona outros sistemas produtivos que buscam a sustentabilidade, desenvolvimento e responsabilidade como forma de cumprimento de seus objetivos, enquadrando-se neste contexto as organizações do primeiro e terceiro setor.

\section{Procedimentos metodológicos}

O presente estudo foi caracterizado como um estudo de caso aplicado, com enfoque exploratóriodescritivo, que visou proporcionar maior conhecimento do problema ao descrever as características do fenômeno estudado e estabelecer as relações entre as variáveis.

Este estudo valeu-se de uma abordagem múltipla quali-quantitativa, principalmente pela subjetividade do sujeito (Organização Não-Governamental), que ajudou na interpretação do fenômeno e na atribuição de significados, gerando categorias de variáveis por meio da análise de conteúdo. Assim, os dados foram coletados de forma qualitativa, através de entrevistas semi-estruturadas e observação do ambiente, e de forma quantitativa, através de questionários fechados. As entrevistas foram todas gravadas e posteriormente tratadas pelo método de análise de conteúdo de Bardin (1977).

O método adotado foi o de estudo de caso e teve como unidade de análise foi a ONG "Projeto Beira da Linha" bem como seus funcionários (em níveis gerencial e operacional), sendo que a amostra foi escolhida com antecedência, pois a pesquisa definiu como participantes a equipe gestora da referida ONG responsável pelas decisões e coordenação das ações (análise qualitativa), bem como foi considerada a amostra os funcionários vinculados à ONG (análise quantitativa).

O presente estudo cumpriu as seguintes etapas: a delimitação dos domínios do estudo sobre gestão por competências, provindo da codificação efetuada no momento da construção do guia da entrevista e da 
literatura pesquisada, permitindo assim relacionar seis domínios bases do estudo, apontados neste estudo, que são:

- Objetivos Organizacionais - caracteriza-se como um domínio composto de um conjunto de metas e propósitos que a organização pretende alcançar dentro de um período de tempo previamente estipulado;

- Competência Organizacional - compreende um repertório de comportamentos e capacidades que algumas organizações dominam, o que as faz se destacar de outras, em contextos específicos;

- Competência Individual - trata-se de um estado quantitativo e temporal de uma pessoa para executar uma tarefa ou missão;

- Discrepância de Desempenho - composto pelo gap decorrente quando se compara o desempenho real e o desempenho esperado;

- Expressão de Competência - concernente ao um conjunto de conhecimentos mínimos para um desempenho satisfatório especificando a ênfase da competência; e

- Capacidade de Entrega - que exprime o envolvimento de cada pessoa dentro de todo o processo.

Com base nos domínios classificados preparamos o guia para a entrevista, que teve como objetivo colher informações sobre a atuação da ONG e o papel de cada pessoa inserida na mesma. Foi realizada uma entrevista com o fundador do PBL, buscando informações gerais sobre as competências das ONGs e, especificamente, sobre as competências que regem o PBL desde a sua fundação. Nesta mesma etapa, fizemos também entrevistas com a equipe gestora, envolvendo o presidente atual do PBL, a coordenadora pedagógica bem como todos aqueles que são responsáveis pelas diversas áreas de atuação do PBL (profissionalizante, esporte, cultura, administrativa e pedagógica). Para a realização das entrevistas semiestruturadas foram oferecidas explicações das razões da pesquisa e apresentado brevemente o guia a ser seguido. Gravadas em áudio, foram realizadas individualmente, tendo em média a duração de 30 a 40 minutos, feitas no próprio local de trabalho, em vários ambientes. Por ser uma instituição com grande fluxo de pessoas, tivemos, em algumas entrevistas, interferências no ambiente físico, com interrupções de pessoas e ligações telefônicas, o que pode ser caracterizado como uma limitação deste estudo.

Por fim, foi realizada a transcrição das entrevistas para dar inicio à análise dos dados, sendo que as informações colhidas foram analisadas e interpretadas através da utilização de técnicas descritas de Análise de Conteúdo baseadas nos estudos de Bardin (1977). Procedeu-se a análise de textos, parágrafos, frases e comentários dos entrevistados, visando uma categorização temática dentro de domínios prédefinidos, conforme os fundamentos conceituais. Para tanto, foi necessário ler, reler e interpretar as respostas uma a uma, buscando captar o sentido da asserção. Assim, os dados contidos na transcrição foram organizados, transformando dados brutos em elaborados, através de uma categorização, na qual observou-se a unidade de análise pré-definida na pesquisa, visando compreender a realidade do conteúdo explícito e implícito através de análise interpretativa, considerando-se, como unidade de registro, o tema ou aspecto alusivo a cada um dos seis domínios e, como unidade de contexto, o parágrafo que continha o tema a ser analisado.

A presença física dos pesquisadores no ambiente da $\mathrm{ONG}$, contribuiu para ao processo de observação que contemplou o estudo do ambiente funcional e o acesso aos seus documentos, contribuindo para o estabelecimento do roteiro da entrevista e a escolha das pessoas entrevistadas (coordenadoras do PBL).

A segunda etapa do estudo deu-se após as entrevistas, quando foi elaborado um questionário com base nas informações colhidas na primeira etapa, contendo dez perguntas fechadas de múltipla escolha, do tipo "Likert", e três perguntas abertas, cuja validação se deu através de um pré-teste aplicado pelos autores para sanar quaisquer dúvidas quanto à interpretação das perguntas nele contidas. Posteriormente aplicamos o questionário aos demais talentos vinculados ao PBL - na maioria educadores - o que permitiu 
um aprofundamento nos aspectos relevantes da questão investigada, dos pontos ainda obscuros e da existência de eventuais polêmicas.

As inferências neste estudo foram feitas desde o contato com a ONG, através da observação e participação cotidiana, pelas entrevistas realizadas, pelos questionários aplicados e, a partir da referência e confronto com a literatura pesquisada, foi possível apresentar conclusões e sugestões referentes às competências organizacionais e pessoais da referida ONG.

\section{Análise dos dados e interpretação dos resultados}

A revisão da bibliografia ofereceu ao estudo parâmetros sobre os princípios da gestão por competências e, tendo como perspectiva a pessoa certa no lugar certo, puderam ser definidos os domínios que fundamentaram o guia de entrevista aplicada junto aos gestores, cujos dados ofereceram suporte para definição das categorias de acordo com cada domínio.

Assim, em relação ao domínio "objetivos organizacionais" puderam ser definidas como categorias de análise os itens que se referiam a: educação popular como eixo principal; criação de políticas públicas e capacitar e formar com qualidade.

No domínio "competências organizacionais", as categorias de análise destacadas foram: diálogo e participação; formação dos profissionais e cultura (arte)/ educação/ profissionalização/ esporte.

Em relação às "competências individuais", os aspectos que mais se destacaram na análise foram: desenvolvimento das competências após inserção no PBL; necessidade de algumas competências específicas e interesse das pessoas em se qualificarem.

O domínio "expressão de competência" pode ser identificado principalmente pelas ações de: Educação popular; trabalho sócio-educativo e conhecimento específico na área de atuação.

Como categorias de análise para o domínio "discrepância de desempenho" foram destacadas como relevantes a observância a respeito de: dificuldade em elaborar um planejamento estratégico; necessidade de organizar de forma racional as atividades e as ações pensadas são maiores do que as pessoas podem realizar e.

Como último domínio do estudo, ficou definido que "a capacidade de entrega" poderia ser identificada ao se analisar: a afetividade como fator de entrega; a presença da participação e da doação profunda e, se há uma sincera adesão e sensibilidade por parte das pessoas.

Através da segunda fase do estudo voltada para os funcionários do PBL, de forma geral pode-se constatar que os respondentes associam as competências de uma ONG a ações como: solidariedade; apoio a grupos carentes; parceria e movimento/ação.

Ao se tratar especificamente da percepção, os respondentes em relação às ações do PBL destacaram-se aspectos como: continuidade da escola; compromisso; espaço de criação; trabalho popular e desenvolvimento da educação, cultura e esporte.

As questões abertas da pesquisa aplicada junto aos funcionários que teve como objetivo sondar a percepção dos mesmos em relação aos domínios "Objetivos Organizacionais" e "Competências Organizacionais" em comparação com a percepção desses conceitos pela equipe gestora. A análise do conteúdo das respostas nos propiciou conhecer que na percepção dos respondentes que as "competências 
organizacionais" foram caracterizadas por: capacidade de fazer acontecer; capacidade de pôr em prática e capacidade de desenvolvimento.

Quanto aos “objetivos organizacionais", os aspectos destacados foram: encontrar um caminho profissional e social; formar cidadãos críticos e capazes de lutar pelos seus direitos; desenvolver lideranças na comunidade; oferecer espaços que ajude a ampliar os conhecimentos; educar, conscientizar, construir saberes valorizando a cultura local e geral; e sensibilizar adolescentes sobre o mercado de trabalho.

Comparando os dados colhidos através dos questionários aplicados junto aos funcionários e a entrevista junto a equipe gestora, pudemos notar a existência da compatibilidade de percepção entre esses dois segmentos em relação ao conhecimento sobre ONGs, sobre a atuação do PBL, bem como as suas competências. Claro que, em relação aos discursos dos gestores, há um vocabulário e uma idéia mais sistemática dos conceitos abordados, mas o foco se encontra no mesmo patamar. Com relação ao termo competência, percebeu-se um conhecimento elementar por parte daqueles que responderam ao questionário, diferente da equipe gestora, que domina muito bem o termo e que foi coerente à explanação dada na teoria.

Em relação aos objetivos organizacionais percebemos que há coerência na percepção dos respondentes que apontaram como foco principal a educação. Quanto à eficácia de suas ações, na análise qualitativa, pudemos verificar que na percepção dos respondentes, o PBL tem cumprido os seus objetivos, principalmente em relação à questão sócio-educativa. Esta informação foi ratificada através dos dados quantitativos, uma vez que 53,84\% das pessoas afirmam que o PBL está sendo eficaz nas suas ação. Entretanto, na opinião da equipe gestora, o PBL ainda possui grandes deficiências em outros campos de atuação.

$\mathrm{Na}$ análise entre os objetivos e as competências organizacionais nota-se que na percepção dos respondentes a ONG possui as competências organizacionais adequadas para atingi-los com sucesso, haja vista que $53 \%$ das pessoas afirmam que o PBL possui as competências organizacionais satisfatórias, reunindo assim, boas condições na execução de suas atividades e conquista de seus objetivos.

De acordo com os respondentes, o grau de entrega das pessoas em suas tarefas e no envolvimento como um todo é bastante positivo. Isto pode ser visualizado pelo resultado da pesquisa, o qual apresenta que $69 \%$ das pessoas percebem esse envolvimento e, quando comparando com a opinião dos gestores, percebe-se a compatibilidade profunda no que foi expresso nas entrevistas sobre a questão do caráter de participação e da construção coletiva. Isso mostra que, neste sentido, há uma sintonia, ou seja, um equilíbrio entre as competências organizacionais e individuais.

Apesar de ser detectado pelos gestores que existe ainda grande deficiência na formação das pessoas que trabalham no PBL, parece que este fator é minimizado quando se percebe um alto nível de envolvimento de todos com os objetivos organizacionais e grande interesse pela busca da capacitação.

Um ponto preocupante apontado pelos questionários é o de que 54\% das pessoas não se sentem no lugar certo ou percebem que as pessoas não estão em seus lugares certos em relação as suas competências, ou ainda que não possuem clareza sobre as mesmas, mas nem por isso se sentem menos motivadas para o trabalho que executam. Esta condição pode contradizer os preceitos teóricos que relaciona a motivação à perfeita compatibilidade entre as tarefas executadas e as competências individuais existentes.

Diante disto, pode-se dizer que, neste estudo, o fato de não ter a pessoa certa no local certo não afeta diretamente na motivação e no envolvimento das pessoas. A seguir, são apresentadas as conclusões e sugestões extraídas desta pesquisa, conforme definido em seus objetivos. 


\section{Conclusões e sugestões}

Esta pesquisa, de caráter quali-quantitativo, propiciou o estudo das competências na área das ONGs, em especial no Projeto Beira da Linha (PBL), nos levando a responder a questão inicial e aos objetivos traçados para este estudo. Em se tratando da concepção do que sejam as competências organizacionais e as competências individuais no PBL, foi visto que há compatibilidade entre elas, havendo, em algumas situações, discrepância de desempenho, fator este superado pela marcante entrega dos membros e representado pela forma atuante em que o PBL vem alcançando muitos dos seus objetivos.

Por meio das análises e da verificação dos resultados da pesquisa, evidenciou-se que, no domínio "objetivos organizacionais", o eixo central está voltado para a educação popular, políticas públicas e a capacitação e formação com qualidade; no domínio "competências organizacionais", concluiu-se que a base das competências do PBL se centra no diálogo e participação na formação de seus profissionais e num trabalho voltado para a arte, educação, profissionalização e esporte; já no domínio "competências individuais", percebe-se um desenvolvimento das competências após a inserção dos profissionais, mas também uma carência de algumas competências mais específicas e um interesse profundo por parte das pessoas em se qualificarem cada vez mais; em relação ao domínio "expressão de competência", a ênfase é dada na educação popular, no trabalho sócio-educativo e no conhecimento específico de atuação que o PBL possui, traduzindo uma competência para executar; já no domínio "discrepância de desempenho", percebeu-se que a lacuna que há refere-se a uma falta de planejamento estratégico, levando em consideração a força de trabalho; e no domínio "capacidade de entrega", verificou-se que há um grande traço de afetividade entre as pessoas e que a participação e o envolvimento é profundo, mesmo quando as pessoas não estão nos "lugares certos", ou seja, pudemos perceber que, apesar de muitas pessoas não estarem atuando de acordo com suas competências individuais, há um grau significante no envolvimento e entrega das mesmas, o que, em nível teórico, pode significar um paradoxo quando se apregoa um vínculo determinístico em relação às funções desenvolvidas/competências individuais e o nível de comprometimento das pessoas para com os objetivos organizacionais.

Isso nos leva à conclusão de que, em organizações não-governamentais, podem existir fatores subjetivos mais consideráveis em relação ao comprometimento, ou que, para organizações desta natureza, o aspecto da motivação (atitude) para o trabalho pode ser mais reforçado quando se fala no tripé que caracteriza teoricamente a Gestão por Competência, o que inclui conhecimentos, habilidades e atitudes. Nesse sentido, a questão de atitudes mais apropriadas à realidade parece ser a chave para o aprimoramento das práticas de trabalho e para o envolvimento de todas as pessoas neste tipo de organização.

Em relação à ONG estudada, pudemos constatar, como já dito, que há uma compatibilidade entre os objetivos organizacionais e o perfil de seus funcionários que parecem compartilhar com seus valores e crenças.

Com o exposto, levantamos uma nova questão: a percepção da ausência do vínculo determinístico em relação às funções desenvolvidas e/ou competências individuais e o nível de comprometimento das pessoas para com os objetivos organizacionais poderia significar que esta regra não se aplica às organizações de cunho social e/ou filantrópico, onde o aspecto subjetivo parece ser mais premente?

Para responder a estas questões, recomendam-se esforços futuros para estudos complementares aplicados em outras ONGs, já que há carência de bibliografia nesta área, principalmente no que se refere ao modelo de gestão por competências. 


\section{Referências}

ALBUQUERQUE, L. G. de; OLIVEIRA, P. M.de. Competências ou Cargos: Uma Análise das Tendências das Bases para o Instrumental de Recursos Humanos. Caderno de Pesquisa em Administração. São Paulo, v. 8, n. 4, p. 13-25, out/dez, 2001.

BARDIN, L. Análise de conteúdo. 70. ed. São Paulo: Edições Persona, 1977.

DUTRA, J. S. (Org.). Gestão por Competências. 2. ed. São Paulo: Gente, 2001. 130 p.

FERNANDES, M. C.. ONGs: a emergência do terceiro setor. 1996. 96 f. Dissertação (Mestrado em Ciências Sociais) - Universidade Federal do Rio Grande do Norte, Rio Grande do Norte, 1996.

FERNANDES, R. C. As Organizações Não-Governamentais (ONGs). In: FERNANDES, R. C. Privado porém Público: O Terceiro Setor na América Latina. 2. ed. Rio de Janeiro: Relume-Dumará, 1994. p. 6585.

FISCHER. O conceito de modelo de gestão de pessoas - Modismo e realidade em gestão de Recursos Humanos nas empresas brasileiras. In: DUTRA, J. S. (Org.). Gestão por Competências. 2. ed. São Paulo: Gente, 2001. 130 p.

FLEURY, M. T. L. Aprendizagem e gestão do conhecimento. In: DUTRA, J. S. (Org.). Gestão por Competências. 2. ed. São Paulo: Gente, 2001. 130 p.

. A gestão de competência e a estratégia organizacional. In : FLEURY, M. T. L. (Org.). As Pessoas na Organização. São Paulo : Gente, 2002. p. 51-61.

FLEURY, M. T. L ; FLEURY, A. C.C. Alinhando Estratégia e Competência. In: Revista de administração de Empresas, volume 44, no.01 - Jan/mar, 2004. p. 44 -57.

GOHN, M. da G. Terceira via, terceiro setor e ONGs: espaços de um novo associativismo. In: GOHN, M. da G.Educação Não-Formal e Cultura Política. São Paulo: Cortez, 1999. p. 64-90.

GREEN, P. C. Desenvolvendo competências consistentes. Rio de Janeiro: Qualitymark, 2000.

HAMEL, G.; PRAHALAD, C. K. Competindo pelo futuro. Rio de Janeiro : Campus, 1995.

LARA, J. F.; SILVA, M. B. da. Avaliação de desempenho no modelo de gestão por competências: uma experiência de utilização. [S.I.: s.n.], 2004.

LE BOTERF, G. Desenvolvendo a Competência dos Profissionais. Porto Alegre : Artmed, 2003.

MATOS, J. F. de. A pessoa certa no lugar certo. [S.I.:s.n.], 2004. Disponível em: $<$ http://www.varejista.com.br/novo_site/print.asp?id=22455> Acesso em: 25/06/04.

MCCLELLAND, D. C. Testing for competence rather than intelligence. American Psychologist, no. 28, p. $1-4,1973$.

RESENDE, E. Remuneração e Carreira Baseadas em Competências e Habilidades. Rio de Janeiro : Qualitymark Ed. ABRH - Nacional, 2002. 
RUANO, A. M.. Gestão por Competência: Uma Perspectiva para a Consolidação da Gestão Estratégica de Recursos Humanos. Rio de Janeiro: Qualitymark, 2003.96 p.

RUAS, R. Gestão Por Competências: Uma Contribuição à Perspectiva Estratégica da Gestão de Pessoas. ENANPAD, Anais, 2003.

TEIXEIRA, E. A. Criatividade, Ousadia \& Competência. São Paulo: Makron Books, 2002. 